\title{
Un pacto con el diablo. Discurso, personajes y acciones de un nuevo espectáculo político
}

\author{
A Pact with the \\ Devil. Discourses, \\ Characters and \\ Actions from a New \\ Political Spectacle
}

\author{
Um pacto com 0 \\ diabo. \\ Discurso, \\ personagens e \\ ações de um novo \\ espetáculo político
}

José Ignacio Correa Medina* ORCID: https://orcid.org/0000-0001-7687-3885

Cecilia Dimaté Rodríguez** ORCID: https://orcid.org/0000-0001-9710-0988
Para citar este artículo

Correa, J. I. y Dimaté, C. (2019). Un pacto con el diablo. Discurso, personajes y acciones de un nuevo espectáculo político. Folios, 50, 23-39. doi: 10.17227/Folios.50-8476

Artículo recibido $27 \cdot 08 \cdot 2018$

Artículo aprobado $25 \cdot 01 \cdot 2019$

en Pedagogía, Lenguaje y Comunicación (GIPELEC). Correo electrónico: jicorrea@pedagogica.edu.co

** Profesora Universidad Externado de Colombia. Líder del Grupo de Investigación en Pedagogía Crítica y Didácticas para la Transformación Social.

Correo electrónico: cecilia.dimate@uexternado.edu.co 


\section{Resumen}

En este artículo de reflexión se lleva a cabo un acercamiento a los atributos de estatidad denominados Aparato administrativo institucional y Capacidad simbólica del Estado, en la dirección de caracterizar el discurso hegemónico de la política colombiana. Para el efecto, y con base en la propuesta teórico-metodológica del Análisis Político de la Significación (APS), se retoman desarrollos conceptuales acerca de la teoría del Estado, las políticas públicas y la estructuración del espectáculo político, con la perspectiva de entender el tinglado en el que se mueven los actores políticos y se implementan las acciones de gobierno. Finalmente, se analizan acontecimientos recientes de la arena nacional y se concluye que dos tipos de mentira (la que aterroriza y la que enardece el ánimo) han propiciado -por primera vez en la historia estatal- el empleo abierto y grosero del doblepensar orwelliano, con lo que se pretende cerrarle el paso a lo que pueda ser la conformación de un discurso contrahegemónico que llegue a constituirse en alternativa de poder.

\section{Palabras clave}

Estado; espectáculo político; análisis político de la significación; doblediscurso; mentira política

\section{Abstract}

In this reflection article, it is carried out an approach to the features of the State conditions: Institutional administrative device and Symbolic capacity of the State in order to describe the hegemonic discourse in Colombian politics. For doing so, and based on the theoretical and methodological proposal of the Political Analysis of Signification, the conceptual development about the theory of State, public policies and the structure of political are taken up for understanding the clutter in which the political actors move and implement government actions. Finally, the recent events of the political arena are analyzed and it is concluded that political lying (the one that frightens and the one that fires up the spirit) have promoted -for the first time in the State history- the open and rude use of Orwell's doublethinking for standing in the way for a counterhegemonic discourse able to become in an alternative of power.

Keywords

State; political spectacle; political analysis of signification; double discourse; political lying

\section{Resumo}

Neste artigo de reflexão, é realizada uma abordagem dos atributos do Estado denominados aparelho institucional administrativo e capacidade simbólica do Estado, no sentido de caracterizar o discurso hegemônico da política colombiana. Para este fim, e com base na proposta teórica e metodológica Análise Política da Significação (APS), os desenvolvimentos conceituais sobre a teoria do Estado, as políticas públicas e a estruturação do espetáculo político são retomados, com a perspectiva de entender o emaranhado em que os atores políticos se movimentam e a implementação das ações do governo. Finalmente, os recentes desenvolvimentos na arena nacional são analisados e conclui-se que as mentiras políticas (que aterroriza e que inflama os espíritos) levaram -pela primeira vez na história estatal- o emprego aberto e grosseiro do duplipensar orwelliano, com que se destina a bloquear o caminho para o que pode ser a formação de um discurso contra-hegemônico que se torna num poder alternativo.

\section{Palavras-chave}

Estado; discurso político; análise política da significação; duplipensar; mentira política 
Un magistral relato da cuenta de un hombre que asiste a la proyección de una película en la que se ve cómo Daniel Brown hace un pacto con el diablo y, como es habitual en este tipo de contratos, Brown promete entregarle su alma; en contraprestación, recibirá del diablo toda suerte de riquezas durante siete años. Mientras observa el espectáculo, el hombre repasa su vida de privaciones $y$, casualmente, termina haciéndose amigo de otro espectador quien le ofrece un negocio que, como podrá haberse advertido, resulta ser la compra de su alma, $y$ así se lo recalca cuando le indica al hombre que "A estas alturas, señor mío, resulta por demás una presentación. Estoy completamente a sus órdenes" (Arreola,1997, p. 269).

Satanizado desde diversas orillas ideológicas, el Estado, al través de uno o dos de sus atributos de estatidad, convoca -de manera abierta, encubierta o, incluso, sobreentendida- a múltiples individualidades y colectivos a participar de sus ejecutorias, cuando no son ellos quienes se consideran con el deber, las capacidades o el derecho de aportar al afianzamiento de ideas que, potencialmente, puedan propiciar la formulación, implementación y evaluación de políticas públicas.

En esta parte del mundo, en la que con dificultad se han ido conformando unos regímenes políticos que responden ora a llamados de las condiciones internas suscitadas por las relaciones políticas y sociales, ora a condicionamientos externos de índole económica e ideológica, fundamentalmente, la pregunta por cómo dialogan el Estado, la sociedad y las políticas en América Latina nos lleva revisar algunos de los planteamientos que, acerca de estas problemáticas, se han hecho en los espacios investigativos del país y el exterior.

De todas maneras, ante la diversidad de posturas y planteamientos, es claro que este trabajo busca más que dar cuenta final de lo que debería ser una única explicación-alumbrar diferentes perspectivas de análisis y allegar propuestas de comprensión que, cada cual en lo suyo, pueden ser de provecho en el ámbito académico que es el que nos ocupa, por ahora. Al efecto, se realiza un acercamiento a algunas de las teorías que dan cuenta de la relación entre el Estado y diferentes individualidades y gru- pos de interés que dan pie a la configuración de un universo simbólico que refuerza las actuaciones del primero y les permite a los segundos constituirse en piezas claves dentro del proceso político ${ }^{1}$, a la vez que se realiza un acercamiento interpretativo, desde el Análisis Político de la Significación ${ }^{2}$, a algunas interacciones que consolidan formas particulares de ejercer el poder y/o de pugnar por él.

\section{Acerca del demonio ${ }^{3}$}

Propio de la tradición teórica occidental es el recelo que existe hacia el Estado, sin que ni el liberalismo ni las corrientes marxistas ni una más reciente concepción de corte foucaultiano logren proponer los elementos suficientes para concebir una organización social que no requiera tal principio

1 En esta dirección, conviene tener en cuenta que múltiples autores -con pretensiones teóricas harto disímiles, pero no por ello menos clarificadoras- han advertido acerca de la influencia de élites intelectuales en el proceso de las políticas públicas, entre ellos, Mill, quien dice que los gobiernos han sido guiados "por el consejo y la influencia de uno o varios mejor dotados e instruidos" (1968, p. 124, citado por Parsons, 2007, p. 199); Keynes, para quien lo realmente importante es la influencia que tienen ciertas individualidades y sus ideas: "Estoy seguro de que se exagera mucho el poder de los intereses creados en comparación con la intrusión gradual de las ideas" (1936, p. 383, citado por Parsons, 2007, p. 199). Posteriormente, podemos encontrar -entre otros muchos- a Hall, Coats y Colander, Kingdom, Sabatier y Jenkins-Smith, de quienes conviene tener en cuenta sus planteamientos acerca de cómo "las redes y las comunidades de políticas públicas (incluyen a políticos, servidores públicos, analistas de políticas públicas, expertos, grupos de interés, etc.) promueven ideas en determinadas áreas de las políticas públicas. Así para explicar cómo ha impactado (o no) cierta idea a cierta política pública hay que analizar a la red 0 a la comunidad en cuestión" (tal como se cita en: Parsons, 2007, p. 198 ss.).

2 Propuesta teórico-metodológica que surge del trabajo doctoral $L a$ (de)formación política como lógica de la construcción de hegemonía (Correa, 2019), fundada en los aportes de Laclau, Mouffe, Foucault, Castoriadis, Verón, Lakoff, Charaudeau y Van Dijk, entre otros.

3 En este trabajo se asumen como sinónimos los significantes

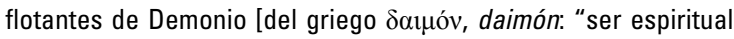
que proporciona saber"], Satán [del hebreo wै, satán: "adversario,

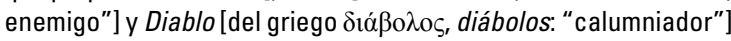
que -a pesar de su origen y sentido diversos- como producto de la mitología judeo-cristiana que ha sustentado gran parte de los imaginarios de nuestra cultura, han adquirido cierta equivalencia, referida a una entidad multiforme, compendio de maldad, de mentira, de traición y de acción real en contra de las especificidades del ser humano que nos permiten concebir la metáfora que aquí empleamos, referida al Estado y, por ende, a quienes participan de la implementación de los atributos de estatidad de que se da cuenta en las líneas que siguen. 
unificador ${ }^{4}$. Ello motivó, hace más de treinta años, a Lechner a plantear la paradoja de que, a pesar de los discursos antiestatales arriba anotados, continuamos preocupados por el Estado y, de paso, lo llevó a compartirnos su sospecha acerca de que "el estado pareciera despertar esa extraña mezcla de fascinación y horror que provoca lo sagrado (y la transgresión de toda interdicción fundacional)" (2000, p. 9). Y, ¿qué es el demonio sino otra cara, por momentos, menos amable de lo sagrado?

Volviendo a la teoría del demonio, es decir, del Estado, es pertinente recordar a Oszlak (2005) quien propone la estatidad como "el conjunto de atributos que permiten reconocer cuando un estado es un estado", a saber: i) gozar de reconocimiento externo de su soberanía política; ii) monopolio del uso legítimo de la violencia física dentro del ámbito territorial; iii) descentralización del control social "a través de un aparato institucional competente y profesionalizado que asegura el ejercicio de la potestad impositiva y la aplicación de las políticas públicas"; y iv) capacidad de producción simbólica claramente manifestada.

En el caso concreto de la conformación de los Estados latinoamericanos y su inscripción en los mercados mundiales, la búsqueda de comprensión transita senderos heterogéneos que -desde ópticas asimismo diferentes e, incluso, divergentes- han buscado explicaciones para las problemáticas que interfieren en la plena organización y funcionamiento de la sociedad en un corpus "cuya expresión activa, autoconsciente y oficial es el estado", (Marx y Engels, 1973, cap. I), mediante la cual las instituciones se objetivan y adquieren forma política. Para el efecto, ha sido necesario trascender la caracterización de "unificación territorial-administrativa que reivindica soberanía 'hacia afuera', monopoliza el poder contra los privilegios estamentales y las autonomías locales 'hacia adentro' y organiza los procesos de acumulación capitalista" (Lechner, 2000, p. 16), tal como puede verse en la profusa lite-

4 A pesar de lo dicho, conviene recordar que Boaventura de Sousa Santos habla de un neoestado (posliberal y posmoderno) y que Roth desarrolla la descripción de una sociedad postestatal. ratura que, al respecto, se ha producido en nuestro continente.

Ya en las décadas de 1970 y 1980, los pensadores políticos latinoamericanos develaron la relación entre el pasado colonial y la conformación de nuestros estados, con miras a dar cuenta de algunas de sus particularidades, en especial lo atinente a las repercusiones de "la sustitución de la autoridad centralizada del estado colonial y la subordinación de los múltiples poderes locales que eclosionaron, luego de la independencia, como consecuencia de las fuerzas centrífugas desatadas por el proceso emancipador" (Oszlak, 2007, p. 137). De esta manera, fue posible que, siguiendo y radicalizando la concepción weberiana, se viera al Estado nacional como sistema de dominación (Oszlak, 2007) o como instrumento de dominación de clase (Laclau, 1981), con unos antecedentes que lo hacen vulnerable a los embates del clientelismo y el populismo (en lo interno) y a la supremacía de Estados poderosos (en lo externo).

Lechner (2000), a su vez, plantea que la investigación acerca del Estado en Latinoamérica presenta cuatro grandes líneas: i) En la década de 1960, bajo la hegemonía conceptual de las teorías acerca del cambio social y del political development, el Estado fue visto desde la perspectiva del régimen político y se lo veía en la dirección de la participación democrática y de los obstáculos que se le presentaban para cumplir las exigencias de toda sociedad moderna. De esta manera, fue posible dar cuenta de las particularidades estructurales de los países latinoamericanos, pero sin abordar las incidencias históricas y sociales en la constitución de nuestros estados. ii) Por la misma época, un corriente de análisis con base en las orientaciones cepalinas ve al Estado como agente de desarrollo económico y cuestiona las estructuras internacionales de dependencia económica a la vez que centra su atención en las políticas públicas, pero cae en el reduccionismo de equiparar al Estado con el gobierno. iii) Posteriormente, se cambia el centro de atención y, más que analizar la cuestión de la dependencia internacional, se aborda la problemática de las estructuras nacionales de dominación $y$, con base 
en el marxismo, se plantea la necesidad de abordar la revolución de las estructuras sociales más que la reforma del estado mismo. iv) Con la proliferación de regímenes autoritarios, los investigadores asumen el Estado como objeto complejo, ya no sólo como instrumento de dominación, sino también en sus relaciones con la sociedad y con otros estados que inciden en lo económico y en lo político.

Vale la pena subrayar cómo, años después, Lechner reconoce en el Estado un carácter afín al de imaginario político definido por Castoriadis $(2003)^{5}$ y amplía los alcances del análisis al dilucidar que

[...] el Estado es más que administración pública, servicios públicos y fisco. Es una configuración determinada del espacio (nacional) y del tiempo (historia). Y esta re-presentación de la totalidad social (aspecto completamente ignorado en las actuales reformas del estado) me parece crucial tanto para la articulación de la diversidad social como para la inserción sistémica del país en los procesos globales. (2000, p. 243).

Tal como lo hemos apreciado, la cuestión del Estado ha mantenido vigencia en el debate latinoamericano, a pesar de la evanescencia del objeto de estudio que acusara Laclau, fundamentalmente recogido por la teoría marxista en tres grandes bloques: i) como epifenómeno que constituye solo un reflejo del diálogo entre las fuerzas y las relaciones de producción; ii) como instrumento de dominación de clase, la cual pareciera desprenderse del anterior pero que resulta, más bien, contradictoria, en tanto si el estado es eficaz para el logro de la hegemonía, no puede ser únicamente el reflejo de las relaciones de fuerza mencionadas; y iii) como instancia de cohesión de una formación social, lo cual constituye una radical ambigüedad entre, por una parte, considerar -en la dirección de Smith- que los mecanismos de reproducción económica (no el

5 Cfr. Castoriadis (1997), quien plantea que tal imaginario es producto del grupo social anónimo en conjunto, no de individuos determinados, y que implica la existencia de unas formas conceptuales nuevas y determinantes que "hacen que exista un mundo en el cual la sociedad se inscribe y se da un lugar. Mediante ellas es como se constituye un sistema de normas, de instituciones [...], de valores, de orientaciones, de finalidades de vida tanto colectiva como individual" (p. 195)
Estado $)^{6}$ garantizaban la cohesión social y, por otra parte, aupar una concepción instrumentalista del Estado (Laclau, 1981).

Adicionalmente, a partir de las anteriores consideraciones, académicos como Oszlak han llevado a cabo gran parte de sus reflexiones y han posibilitado, por ejemplo, su singular recorrido por los orígenes del Estado latinoamericano y, ante todo, le ha dado elementos para -siguiendo a Schmitter, et al. (citado por Oszlak, 2005)- delimitar unos atributos de estatidad que le permiten al Estado: recibir reconocimiento externo de su soberanía política; institucionalizar, internamente, el monopolio del uso legítimo de la violencia física; diferenciar el control social que ejerce a través de órganos especializados con miras al acopio impositivo y al diseño, implementación y evaluación de políticas públicas; y propiciar la internalización de un discurso político hegemónico, de tal manera que continúe siendo posible el ejercicio de la dominación (Oszlak, 2005, 2007).

Para la consecución de los objetivos de este trabajo, son los dos últimos atributos los que más aportan la clarificación pertinente, en la medida en que

a. la descentralización del control social exige la existencia de ese aparato institucional que, si bien es una única y misma entidad, está conformado por individuos para quienes, al decir de Weber, "la ocupación de un cargo es una profesión", lo que implica, aparte de la habitual venta de la fuerza de trabajo, "la aceptación de un deber particular de fidelidad a la administración, a cambio de una existencia segura" (2000, p. 11). Ello significaría que quienes conciben, formulan, implementan y evalúan las políticas públicas forman parte del engranaje estatal, así no pertenezcan a la nómina oficial, en tanto comparten el

6 Recuérdese a este respecto el concepto de guardián de noche, equiparable al de Estado gendarme, concebido como el ámbito ad hoc para dar seguridad al capital privado, el cual resuena en propuestas como la del nuevo ministro de defensa de Colombia, quien pide que se ordene y restrinja la protesta social, en tanto no represente a la totalidad de los colombianos (17 de julio de 2018). Este aspecto se tratará un poco más detenidamete en líneas posteriores. 
halo ideológico del patrón, que definiera Weber, y que fomentan la verdadera gestión profesional del Estado que resultará premiada con impuestos y votos, en la medida en que se dé "la correcta aplicación de los recursos tributarios, la efectividad en la prestación de los servicios públicos, la rendición de cuentas y la oportunidad de participar activamente en la determinación de opciones de política y en el control de la gestión pública” (Oszlak, 2005, párr. 5); como mecanismo que coadyuva al fortalecimiento de la élite que detenta el poder, en clara consonancia con el monopolio del uso de la fuerza ("violencia legítima"); y

b. la capacidad de producción simbólica le apunta a la construcción de un discurso político que, por una parte, se concreta en los hechos, las obras y las conductas de los gobernantes y, por otra, resuena en los medios y redes de comunicación, de tal manera que se construyan universos simbólicos en los que queden claramente diferenciados los "contornos del mundo social, no del mismo modo para todos, sino a la luz de las diversas situaciones desde las cuales las personas responden al espectáculo político" (Edelman, 2002, p. 20). De este modo, resulta válida la construcción simbólica de oponentes políticos con la categoría de enemigos y no de adversarios ${ }^{7} \mathrm{o}$, del mismo modo, resultan viables las coaliciones, incluso con la participación de adversarios, amigos y enemigos que obtienen ventajas materiales y en las que "la ideología, el incentivo material y el lenguaje que los evoca son facetas de la misma transacción" (2002, p. 83). Este aspecto estaría en consonancia con lo expuesto por Sabatier y Jenkins-Smith cuando plantean que quienes busquen tener

7 Todo ello en la dirección schmittiana de considerar que a lo específicamente político corresponde la diferencia entre amigos y enemigos, de tal manera que lo político viene a ser "la esfera de la 'violencia conquistadora'" (Schmitt, 2004, p. 216), en tanto "el enemigo es simplemente el otro" (2004, p. 177). Con el ánimo de enriquecer el debate, puede revisarse lo expuesto en Eco (2013); Mouffe, (2007, 2014) y Habermas (1999). "un impacto significativo en la política [...] deben abandonar el rol de 'técnicos neutrales' y a cambio adoptar el de 'partidarios"' (1993, p. 4), a la vez que -en el interior de un subsistema de políticas- las advocacy coalitions $^{8}$ compiten, con sus convicciones y recursos, por "alterar el comportamiento de las instituciones gubernamentales con miras a alcanzar objetivos específicos en aspectos nucleares de las políticas públicas" (p. 227).

Ahora bien, teniendo como punto de referencia la confluencia de estos dos atributos de estatidad, resulta pertinente hacer un rápido recorrido por los planteamientos de quienes consideran el papel del lenguaje (con sus múltiples posibilidades significativas y mediológicas), con miras a configurar el espacio en el que se representa el espectáculo político que nos concierne. Veámoslo un poco más en detalle.

\section{Acerca del espectáculo político ${ }^{9}$}

Pudiendo tratarse de la escenificación de la obra de algún autor clásico (Esquilo, Shakespeare, Moliere, Calderón u otro análogo) o de cualquiera de las obras de Brecht, para solo citar nombres fundamentales, actividad que requeriría de un cuidadoso entramado y de unas actuaciones a tono con el momento histórico y estético del texto y del espectáculo, la actual política colombiana pareciera estar más cercana a los esperpentos valleinclanescos que al ingenioso descuido de la Commedia dell'Arte. Por ello, no resultaría exagerado parodiar al dramaturgo español del 98 y decir que "la política colombiana, reflejada en los espejos cóncavos, produce Esperpentos [...]

8 El término ha recibido diferentes intentos de traducción, sin que haya podido llegarse a un consenso: coaliciones políticas de 'militantes' (Roth, 2006, p. 37), coaliciones dominantes, coaliciones de defensa, coaliciones promotoras (Parsons, 2007, p. 224). Por ello, en este trabajo se mantiene el término original.

9 Tomamos aquí la caracterización propuesta por Edelman (2002), cuando explica cómo los medios construyen y reconstruyen, con altas implicaciones de la ideología hegemónica, "los problemas sociales, las crisis, los enemigos y los líderes, creando de tal modo una sucesión de amenazas y seguridades" (p. 8), muy en la dirección bruneriana de Realidad mental y mundos posibles. 
Las imágenes más bellas, en un espejo cóncavo, son absurdas" 10 .

No de otra manera es posible entender que el control social ejercido por las ramas del poder público y la producción simbólica se acaballen en la multidimensionalidad de los medios y modos de comunicación contemporáneos para configurar contenidos que generan imaginarios contradictorios o, al menos, lindantes con la esquizofrenia política que campea en la actualidad, encaminados a fortalecer la hegemonía de que se goza o que se está construyendo.

Como se recordará, Dye (1987) plantea que el análisis de la acción política se ha centrado más en lo que hacen los gobiernos que en lo que dicen, lo cual puede extenderse a la política, entendida como todo el espectro "de prácticas e instituciones cuyo objetivo es organizar la coexistencia humana" (Mouffe, 2014, p. 16), las cuales se sitúan en el ámbito ontológico de la conflictividad, es decir, de lo político. Y todo ello nos lleva a intentar una lectura que, partiendo de lo evidente, logre dar cuenta del meollo de algunas actuaciones y algunas representaciones.

Por otra parte, siguiendo a Sabatier (2007), resulta indiscutible el protagonista del espectáculo que nos ocupa: aquel segmento del aparato institucional responsable de la formulación de las políticas públicas, el cual supera el tradicional triángulo de hierro (legisladores, funcionarios y líderes grupales) e incluye a investigadores ${ }^{11}$ y periodistas especializados; y, como actores de reparto, tendríamos a todos aquellos que, no perteneciendo a las élites, constituyen la opinión pública, cuya influencia resulta, cuando mucho, modesta. Habrá, es cierto, algunos comparsas que observan las acciones y que incluso pueden tener intervenciones mínimas y colaterales, entre los que cabe mencionar a grupos

10 En Luces de bohemia, Max Estrella expone el manifiesto estético de Valle Inclán: "Los héroes clásicos reflejados en los espejos cóncavos, dan el Esperpento. El sentido trágico de la vida española sólo puede darse con una estética sistemáticamente deformada [...]. Las imágenes más bellas en un espejo cóncavo son absurdas" (Escena Duodécima).

11 En esta categoría Sabatier incluye, entre otros, a académicos, científicos universitarios, analistas de políticas públicas, consultores (2007, p. 192) de presión, algunos analistas y académicos de escasa participación o poco interés en el asunto.

Ahora bien, el escenario estaría constituido por los subsistemas de políticas, conformados por un grupo de advocacy coalitions jerarquizadas, caracterizadas a su vez por unas convicciones y unos recursos que resultan diferenciados. Estos subsistemas, finalmente, interactúan entre ellos y con el universo cultural, social, legal, económico e institucional que le da origen.

En forma concomitante, el libreto está dado por una serie de argumentos que pueden ofrecerse en aras de alcanzar un consenso entre las coaliciones, siempre y cuando se trate de sistemas políticos de carácter pluralista, pero resultará poco útil en aquellos regímenes centralistas e, incluso, marcadamente presidencialistas. Aquí, incluso, es viable la construcción ideológica de un otro que justifique nuestra particular forma de ser en el mundo, en tanto "tener un enemigo es importante no solo para definir nuestra identidad, sino también para procurarnos un obstáculo con respecto al cual medir nuestro sistema de valores y mostrar, al encararlo, nuestro valor" (Eco, 2013, p. 14), no importa que - para el efecto-debamos hacer uso de la mentira y el odio, graficados de forma magistral por Orwell en 1943,1946 y $1948^{12}$.

12 Hablamos de Politics and the English Language (1946), ensayo en el que desnuda la manipulación lingüística por parte del poder, el cual dice en su párrafo final que "el lenguaje político $-y$, con variaciones, esto es verdad para todos los partidos políticos, desde conservadores a anarquistas- está diseñado para lograr que las mentiras parezcan verdades y el asesinato, una acción respetable, y para dar apariencia de solidez al vacuo vienton; de La libertad de prensa (2010 [1943]): " ¿Y quiénes son estos enemigos? Parece que no solo son quienes la atacan abierta y concienzudamente, sino también aquellos que 'objetivamente' la perjudican propalando ideas erróneas. En otras palabras: defendiendo la democracia acarrean la destrucción de todo pensamiento independiente" (p. 38); y de 1984 (2016 [1948]): "Saber y no saber, tener plena conciencia de algo que sabes que es verdad y al mismo tiempo contar mentiras cuidadosamente elaboradas, mantener a la vez dos opiniones sabiendo que son contradictorias y creer en ambas [...]. Esa era la mayor sutileza; inducir conscientemente a la inconsciencia" (p. 43), aspecto este último que se evidencia en los Dos minutos de odio que llevan al portagonista a sentir una rabia abstracta y sin finalidad, máxime cuando "en un momento de lucidez, Winston descubrió que estaba gritando con los demás y dando patadas con violencia contra el marco de la silla. Lo más horrible de los Dos minutos de odio no era que la participación fuese obligatoria, sino que era imposible no participar" (p. 21). 
Abordaremos ahora algunos aspectos acerca de la puesta en escena, dada la importancia que ciertos planteamientos teóricos le asignan al manejo del lenguaje y su papel en la socialización de lo que no necesariamente forma parte de la racionalidad tradicional:

Toda élite se defiende y afirma en nombre de los símbolos de un destino común. Esos símbolos son la "ideología" del orden establecido, la utopía de los grupos antiélites. Mediante el uso de palabras y gestos autoritarios, la élite arranca sangre, trabajo, impuestos y aplausos a las masas. (Lasswell, 1959, p. 31, citado por Parsons, 2007, p. 208).

En primer lugar, tengamos en cuenta que el discurso construye al sujeto ${ }^{13}$ y a sus representaciones, en el doble sentido de imagen mental y de puesta en escena. Tal vez por ello, Edelman (2002) estudia las políticas públicas como creaciones de los públicos que tienen algún interés en ellas y a las personas que participan de acciones políticas las ve desde dos perspectivas: "Primero, sus acciones y su lenguaje crean su subjetividad, su sentido de quiénes son. Segundo, las personas que participan en política son símbolos para otros observadores" (p. 8). Así, creadores de símbolos y símbolos a su vez, los individuos entran a representar el papel que les corresponde en función de su ubicación en las jerarquías social, cultural y política, y la conciencia que tengan de ello les permitirá alcanzar el éxito o experimentar el fracaso en su representación, tal como lo ha expuesto Charaudeau (1983, pp. 37-57). Solo que la interpretación hará parte tanto de la actuación como del conocimiento que de ella hayan interiorizado $y$, de esa manera, será posible concluir que para cada contrato comunicativo existen palabras y acciones ritualizadas que ofrecen alternativas de comprensión al interlocutor pero cuya elección, no necesariamente, es libre y universal, incluso -más bien- priman las restricciones y el alejamiento de toda forma de creatividad, con contados casos excepcionales como los que menciona Edelman, para concluir afirmando que "no

13 Idea clave de Foucault, Heidegger, Lacan, Derrida, Ricoeur, Laclau y Mouffe, entre otros. es la creatividad la que en tales casos se impone a una audiencia, sino más bien el hecho de que se le dice lo que quiere escuchar en un contexto que hace creíble el mensaje" (Edelman, 2002, p. 131), muy en la dirección de la clasista defensa que Lope de Vega hace de sus comedias:

Porque, como las paga el vulgo, es justo

Hablarle en necio para darle gusto.

(El arte nuevo de hacer comedias en este tiempo, 1609).

Y, como lo sabemos, la credibilidad tiene también su origen en el discurso oficial y sus particularidades. No presentan la misma pertinencia ni, por ende, alcanzan la misma eficacia el uso de vocativos como compatriotas o colombianos; la denominación del mismo tipo de reuniones con comunidades como consejos comunales de gobierno, acuerdos para la prosperidad o talleres Construyendo país; o, en el universo orwelliano que tan magistralmente retrata al Estado en acción, ese doblepensar que surge con la intención de

[...] decir mentiras descaradas creyendo sinceramente en ellas, olvidar cualquier hecho que se haya vuelto incómodo, y luego, cuando vuelva a hacerse necesario, sacarlo del olvido el tiempo que haga falta, negar la existencia de la realidad objetiva y al mismo tiempo reparar en la realidad que uno niega resulta imprescindible. (Orwell, 2016, p. 127).

Esta situación tiene su máxima expresión en Estados como los nuestros en los que se hace eco del presupuesto del devil shift, entendido como la tendencia a magnificar las características negativas de los contradictores, subestimar su fiabilidad y sobrestimar sus posibilidades de acceder al poder, con lo que se acrecientan las distancias entre coaliciones pero se estrechan los lazos al interior de las mismas (Sabatier, 2007, p. 194). Tal vez ello coadyuve a potenciar el efecto que el aprendizaje de las políticas tiene en el largo plazo sobre las agendas y las decisiones de gobierno, mucho más eficaces que el ejercicio mismo del poder. 
Ahora bien, siguiendo a Edelman (2002), tenemos que convenir en que las palabras y los símbolos van en la dirección del triunfo, aunque no necesariamente ocurra igual con las políticas públicas, en la medida en que se está ante una ficción creada por quienes buscan preservar el statu quo, apoyar a los poderosos, torpedear el cambio y actuar contra los que carecen de poder, de tal manera que pueda llegarse a la conformación de un banco de situaciones problemáticas que representan para sus creadores construcciones ideológicas, beneficios o formulaciones ambiguas; mientras que las potenciales soluciones se encuentran ligadas a mecanismos que buscan la adhesión de personas, grupos, organizaciones y causas interesados, a la vez que con la determinación de los problemas ${ }^{14}$ se legitima un tipo particular de autoridad o se formulan los problemas para justificar soluciones previamente establecidas.

No obstante, desde una perspectiva menos apocalíptica, pero igualmente simbólica, Majone (2005) reconoce que "los miembros de una comunidad de políticas representan intereses diferentes, tienen valores diferentes y pueden participar en programas de investigación diferentes, pero todos ellos contribuyen al desarrollo de las políticas al generar y debatir ideas y propuestas nuevas" (p. 208). Con ello abre la puerta a la consolidación de un escenario en el que se representan ideas que deben argumentarse adecuadamente, en función de los intereses, los alcances y las ejecutorias, y no solamente se busca encubrir las pretensiones de las políticas públicas con símbolos, mitos y palabras que solo benefician a los diseñadores de tales políticas.

\section{El análisis político de la significación}

En anteriores trabajos hemos hablado de unos acercamientos a la comprensión de los discursos, como metodología de análisis político que -fundada en los trabajos de Heiddeger, Wittgenstein, Foucault,

14 Indistintamente se manejan en este trabajo las expresiones problema y situación socialmente problemática, a pesar de las diferencias que pueda suscitar su empleo, debido a que los autores consultados tampoco muestran un consenso al respecto. Pero, aclaramos, nos referimos a la misma realidad: aquella a la que busca dar solución una política específica.
Derrida, Lacan y Gramsci, entre otros- dio pie a la estructuración de la propuesta analítica de Laclau y Mouffe (2006) en la que la hegemonía se erige como categoría central, y la noción de lo social -concebido como un espacio discursivo en el que se configuran múltiples relaciones de representación- adquiere un lugar preponderante ${ }^{15}$.

Se trata, pues, de trascender el ámbito meramente lingüístico de los análisis anteriores ${ }^{16}$, en los que se privilegiaban aspectos cuantitativos tales como frecuencia léxica y extensión de las cláusulas, o se abordaban aspectos estilísticos como tipo de léxico empleado y maneras de introducir los temas en la configuración discursiva. De amplio reconocimiento gozan los trabajos analíticos de Lope Blanch, en los que termina haciendo mutis por el foro, para continuar con la metáfora del espectáculo político, cuando se excusa de no ahondar en los alcances simbólicos de los discursos abordados por ser solo un aprendiz de filólogo, con lo que restringe el análisis a los aspectos puramente formales, alejados por completo de los estudios contemporáneos e, incluso, de incipientes -en su momento- interdisciplinas que fueron ganando lugar de privilegio y proyectaron el sentido más allá de lo dicho, es decir, que no se quedaron en las explicaturas sino que buscaron las implicaturas de cada discurso: "Tampoco he querido hacer divagaciones sociolingüísticas sobre el contenido de ciertos pasajes del discurso, a que tan aficionados son muchos lingüis-

15 Alrededor de 2010 comenzamos a incursionar en el análisis político del discurso y hemos venido presentando hallazgos parciales en ponencias (ALED, Seminario Andrés Bello del ICC), conferencias y charlas (Universidad Pedagógica Nacional, Universidad Externado de Colombia, Universidad Autónoma de Colombia, Universidad de Nariño, Universidad Pedagógica y Tecnológica de Colombia, entre otras), debates y publicaciones, entre las que sobresale: “El Análisis Político del Discurso: diálogo entre Ciencias del Lenguaje y Ciencia Política" (Correa y Dimaté, 2011).

16 Aunque pareciera cosa del pasado, este tipo de análisis pervive, en especial en quienes tienen formación en cierta escuela histórica y política francesa. Un caso emblemático es el de María Fernanda González E., asidua analista de El Tiempo y otro medios, quien da cuenta de "las claves del discurso" presidencial, asumiendo-como lo ha hecho en otras ocasiones, con otros personajes- "Las palabras más reiterativas son: construir, diálogo, compromiso, escuchar, pensar y soñar", sin entender que se trata de significantes vacíos que se llenan con la ideología del grupo gobernante y que es allí donde adquieren pleno valor y contundencia (cfr. González, 2018). 
tas contemporáneos" (1987, p. 222), para concluir su estudio empleando un refrán del siglo XVII, lo que le adiciona cierto tufillo anquilosante a sus apreciaciones: "'A ti lo digo, hijuela; entiéndelo tú, mi nuera, porque incursiones de tal naturaleza no son propias del aprendiz de filólogo”.

Ahora, y como resultado de los cuestionamientos a ese análisis gramatical del discurso y a la propuesta laclausiana por un laberíntico sesgo deconstruccionista y posmoderno que dificulta su implementación metodológica, se configuró un acercamiento al análisis que retoma aspectos claves de Laclau y Mouffe para ponerlos en diálogo con actuales desarrollos teóricos de las ciencias del lenguaje y de los estudios políticos (cfr. Correa, 2019), a la que hemos denominado análisis político de la significación (APS).

El Aps parte de una concepción de discurso que -alejándose de una perspectiva nominalista y taxonómica, con pretensiones ontológicas, que buscaba asignar nombres a las cosas y dar cuenta de su ser en tal nombre (cfr. Foucault, 1985, pp. 326-331)pueda albergar todas las producciones simbólicas que median las relaciones entre los individuos, con la intuición teórica de que cualquier objeto, proceso o cualidad es potencialmente un signo de otra realidad, si así lo admite un interlocutor, en tanto “está en su lugar no en todos los sentidos, sino en relación a un tipo de idea, que a veces he llamado la base del representamen" (Peirce, 1978, p. 22), y con la intuición poética de que “ $\mathrm{i} A \mathrm{~h}$, todo es símbolo y analogía! / El viento y esta noche tan fría / Son otra cosa que noche y viento [...]" (Pessoa, 1989, p. 49). En consecuencia, se entenderá que el discurso está conformado por la producción simbólica que lo vehicula y por todas las condiciones del contrato de comunicación y las intencionalidades que subyacen a las estrategias de esa particular mise en scène ${ }^{17}$ (Charaudeau, 1983, p. 50 y ss. $)^{18}$. De esta manera, se

17 Continuando con la analogía del espectáculo, se retoma aquí la denominación que asigna Charaudeau, que -como se sabe-goza de prestigio en las artes escénicas de todo el mundo y que no es otra cosa que puesta en escena o escenificación.

18 No olvidar que Foucault distingue unas prácticas discursivas de otras no discursivas, postura que entra en contradicción con principios semióticos, políticos, analíticos y discursivos, razón por la cual su propuesta no es tenida en cuenta en este trabajo. asume que la negociación de sentidos entre locutores e interlocutores permitirá la confluencia, interacción y eclosión de referentes, saberes, estilos y temáticas que - no siendo continuos ni aglutinables- tenderán hacia una regularidad en la dispersión, con lo que se asumirían los valores simbólicos del ordenamiento, las correlaciones, las funciones, la generación, la transformación y la desaparición de significantes y significados (Foucault, 2013, pp. 54-55).

Con estas premisas, el análisis que se lleve a cabo se centrará en los procesos de significación más que en el discurso mismo, algo emparentado con la Verstehen weberiana que, al decir de Hekman, buscaba desentrañar "los significados intersubjetivos o las reglas socialmente constituidas que definen el sentido de un hecho dentro de una sociedad dada" (1983, p. 43, citada por Ritzer, 1996, p. 253) y deudor, en mucho, de la propuesta crítica de Laclau y Mouffe, heredera del marxismo, el psicoanálisis y el pensamiento posmoderno, que conforma un todo que recoge las críticas de Lyotard a las grandes narrativas de la modernidad, de tintes universalistas que subyugan cualquier otro tipo de narrativas, en especial las del conflicto, la diversidad y lo alternativo; la concepción antifundacionalista de Rorty (citado por Howarth, 1997, p. 127) que rescata el carácter dinámico del pensamiento y la sociedad en oposición a la búsqueda de fundamentos últimos que constituyen "intentos de hacer eternos ciertos juegos del lenguaje, prácticas sociales o imágenes de uno mismo totalmente contemporáneas [o sea, históricamente específicas]"; y el antiesencialismo que Derrida asocia con "la imposibilidad de acotar la esencia de las cosas y la de precisar completamente la identidad de las palabras y los objetos" (citado por Howarth, 1997, p. 127).

Sobre esta base, se retoman los elementos de un sistema analítico que incluye componentes como

De igual manera, Laclau y Mouffe (2006) argumentan su rechazo a tal concepción por las restricciones que implica para el nuevo concepto de discurso y por la pervivencia de la escisión entre lo material y lo mental en el ámbito discursivo: “Suponer lo contrario es aceptar una dicotomía muy clásica: la existente entre un campo objetivo constituido al margen de toda intervención discursiva y un 'discurso' consistente en la pura expresión del pensamiento" (p. 147). 
ideología ${ }^{19}$, articulación ${ }^{20}$, antagonismo ${ }^{21}$ y hegemonía, asumida esta última como la categoría central de todo el aparato analítico, razón por la cual se le dedicarán algunas líneas a su dilucidación.

Como se recordará, el concepto de hegemonía busca distinguirse de otras configuraciones simbólicas a las que podrían remitir sus haces semánticos y, gracias a los desarrollos gramscianos, podemos asumirla como la función de dirección que desempeña el grupo dominante sobre el conjunto de la sociedad -en los ámbitos político, intelectual y moral- con la claridad de que este grupo es resultante de la articulación de las clases dirigentes, sin que las clases subalternas hayan logrado convertirse en Estado, esto es, unificarse (Gramsci, 2007, p. 491). Con estos presupuestos, la expansión de las clases dominantes, a su vez, configurará un campo en el que convergen los componentes categoriales arriba anotados, gracias a lo cual éstas lograrán imponer sus imaginarios y su discurso al resto de la sociedad, mediante la construcción de un nosotros que no es más que una máscara puesta sobre el rostro del yo que representa tal articulación (cfr. Charaudeau, 1983, pp. 7-8).

Con lo expuesto, se busca desentrañar la significación política que conllevan todos los discursos, sin importar cuál sea su ámbito de producción, en

19 Para este trabajo, se emplea una noción cercana a "la actualización del horizonte imaginario que proporciona significación a las configuraciones discursivas, con la ostensible salvedad de que las ideologías totalitarias tienden al cierre de todos los discursos en torno a un principio único (en el plano interno) y unificador (en su manifestación externa)" (Correa y Dimaté, 2011, p. 97). No obstante, con ella no se elude el debate acerca de este concepto en la filosofía y en la ciencia política, el cual está en la base de cualquier configuración semántica al respecto.

20 Asumida, en términos llanos, como "toda práctica que establece una relación tal entre elementos, que la identidad de estos resulta modificada como resultado de esa práctica" (Laclau y Mouffe, 2006, p. 142), con lo que se constituye una entidad de orden superior. Es importante resaltar aquí los ecos del estructuralismo postsaussureano que postuló la doble articulación del lenguaje.

21 Mouffe $(2014$, p. 15) reconoce que el antagonismo es una posibilidad presente en toda ordenación social, en tanto "la sociedad está marcada por la contingencia y todo orden es de naturaleza hegemónica: es decir, es siempre la expresión de relaciones de poder", lo cual complementa lo expuesto en Laclau y Mouffe (2006, p. 169) acerca de que el antagonismo "lejos de ser una relación objetiva, es una relación en la que se muestran-en el sentido en que Wittgenstein decía que lo que no se puede decirse puede mostrar-los límites de toda objetividad". El concepto de antagonismo supera la oposición schmittiana de amigo/enemigo que dio pie a múltiples teorizaciones y acciones políticas concomitantes. la medida en que son portadores de información acerca de las relaciones entre los sujetos sociales y su rol político, así como acerca de la comprensión del lugar que se ostenta o se padece en la construcción de hegemonía.

\section{Atributos en acción}

Recuérdese que hemos delimitado los alcances de este trabajo a dos de los atributos propuestos por Oszlak (descentralización del control social y capacidad simbólica del Estado). Al respecto, los abordaremos de manera solidaria, en un dialogismo que dará pie -también- a una clarificación de los otros dos atributos de estatidad.

La disposición lingüística, apalancada por la disposición cultural e ideológica, ha permitido la consolidación de un universo discursivo que apunta a soliviantar la disposición tímica ${ }^{22}$ de los ciudadanos, de tal forma que puedan construirse imaginarios alrededor de enemigos que inciden en la hegemonización de un pensamiento único: el mantenimiento del statu quo y la alternancia entre una clase política tradicional y una emergente que recoge no un ideario conservador de las tradiciones sino que se empeña en retrotraer la acción política a contextos temporales en los que primaban el autoritarismo de una minoría y la sumisión de la mayoría. Al respecto, basta recordar lo que ha dado en llamarse posverdad, entelequia con la que se busca reducir los alcances vergonzantes de la perniciosa carrera que ha realizado la mentira política, anunciada desde 1712 por Swift, en su particular empleo de la ironía demoledora ${ }^{23} \mathrm{y}$ denunciada por Orwell ${ }^{24}$ en diversos momentos de su vida periodística y literaria.

22 Entendida como aquel funtivo que propicia la negociación simbólica desde los universos emocionales de los interlocutores, la cual es caracterizada -a su vez- por una discursividad no reflexiva (Correa, 2019).

23 Swift -ese formidable enemigo de la corrupción, el belicismo y la injusticia-satiriza una pretendida legitimidad de la mentira política que se fundaría en los distintos derechos al acceso a la verdad: verdades privada y económica que pueden llegar a ser generales, no así la verdad política, puesto que "el pueblo no tiene derecho alguno a pretender ser instruido en la verdad de la práctica del gobierno, como tampoco tiene derecho a pretender poseer grandes patrimonios, tierras o casas señoriales" (2011, p. 35).

24 Cfr. la parte inicial de la nota 12 , en cuanto concierne a Politics and the English Language. 
Para ejemplificar lo expuesto, bastará con recordar las múltiples verdades a medias o las tergiversaciones plenas que han circulado por el ambiente nacional en los últimos años: en primer lugar, la campaña del "No" en el Plebiscito que buscaba refrendar los acuerdos de paz entre el gobierno colombiano y las FARC (evidenciada en múltiples medios y redes) ${ }^{25}$, oficializada el día 6 de octubre de 2016 por Juan Carlos Vélez - gerente de la campaña- al diario $L a$ República, donde manifiesta abiertamente la estrategia mistificadora de su grupo político, encaminada a que los colombianos salieran a votar "verracos", gracias al manejo inescrupuloso de la indignación, el miedo, el fanatismo y la desinformación. Todo ello, documentado por la prensa nacional, muestra cómo perviven y actúan fructíferamente las dieciochescas mentiras que aterrorizan $[\phi o \beta \varepsilon \rho o v]$ y las que enar-

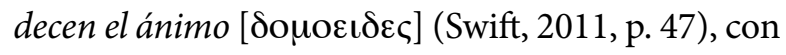
particularidades tales como: "Descubrimos el poder viral de las redes sociales. Por ejemplo, en una visita a Apartadó, Antioquia, un concejal me pasó una imagen de Santos y 'Timochenko' con un mensaje de por qué se le iba a dar dinero a los guerrilleros si el país estaba en la olla. Yo la publiqué en mi Facebook y al sábado pasado tenía 130.000 compartidos con un alcance de seis millones de personas" (Vélez, 2016c).

A manera de colofón, se anota cómo - a pesar de los múltiples cuestionamientos de políticos, periodistas y magistrados- en sus huestes solo genera un reproche, no por la actuación mezquina sino por haber develado la estrategia que utilizó tal campaña:

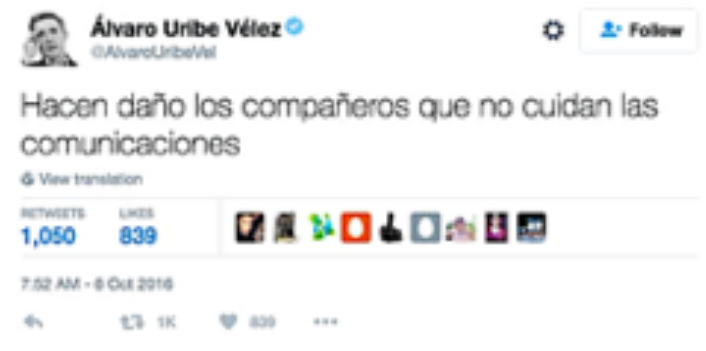

25 Mencionamos solo algunas, las cuales -a su vez-remiten a otras: “Audio [de la] entrevista [a] Juan Carlos Vélez Uribe", (Vélez 2016a), “'El no en el plebiscito ha sido la campaña más barata y efectiva de la historia': Juan Carlos Vélez" (Vélez, 2016b) y "Estábamos buscando que la gente saliera a votar verraca" (Vélez, 2016c); análisis del audio de la entrevista (Coronell, 2016).
Clara concreción de una de las doce trampas que Lakoff recomienda evitar (el juego de las acusaciones) y que deja en evidencia que "los líderes conservadores mienten a menudo y usan un lenguaje orwelliano para distorsionar la verdad y, sin duda, los medios de comunicación se sienten cómodos repitiendo los marcos conservadores" (2013, p. 40).

Por otra parte, aunque en una dirección complementaria que nos ayuda a entender otra situación, Swift dijo en 1726 que

Hay tres procedimientos mediante los cuales un hombre puede acceder al cargo de primer ministro. El primero consiste en saber disponer juiciosamente de la esposa, hija o hermana; el segundo, en traicionar o desacreditar a su predecesor; y, el tercero, en mostrar ante las asambleas públicas un arrebatado entusiasmo contra las corrupciones de la corte. (2000, p. 22).

Podemos acercarnos a los dos últimos para hablar del actual cuerpo de control social, ya que del primero no tenemos evidencia alguna.

Como ha quedado documentado, el actual cuadro administrativo burocrático (Weber, 2012) del régimen político colombiano ha dado en ofrecer una serie de sainetes que ponen de manifiesto no la frescura del teatro del absurdo, sino, primordialmente, un psicodrama lindante con la esquizofrenia del doblepensar o, puesto en los términos laclausianos, una serie de discursos que parecieran inconexos se convierten en enunciados de un discurso articulado por la pretensión hegemónica del grupo dirigente.

Un caso ostensible lo constituye el accionar divergente de un partido político que se ufana de tener el poder $y$, a la vez, da trazas de continuar en la oposición, tal como ocurrió el 7 de agosto de 2018, cuando publica un aviso de prensa, de una página, en el diario El Tiempo (Centro Democrático, 2018), en el que se va lanza en ristre contra el gobierno que concluye $y$, en un lodazal de mentiras o de medias verdades, intenta poner a navegar su proyecto de 'renovación' de las costumbres políticas; por otra parte, el mismo día, el presidente del Senado, Ernesto Macías -del mismo partido- da la 
bienvenida al nuevo presidente de la República con un discurso (Noticias Uno Colombia, 2018) que es clara muestra de cómo se reconstituye un imaginario como el de los dos minutos de odio (Orwell, 2016) con el ánimo de generar adscripciones irrestrictas, empleando palabras que reafirman lo dicho en el aviso de "publicidad política pagada", como advierte el periódico mencionado. Por su parte, el presidente que se posesiona afirma que

Hoy llega a la Presidencia de Colombia una nueva generación, motivada por el servicio y no por el ejercicio vanidoso del poder, comprometida con el futuro y sin anclas en prejuicios del pasado, inspirada en la justicia social y en la seguridad como el cimiento de nuestras libertades, y dedicada a promover el entendimiento, el trabajo en equipo y la construcción de consensos. Es una generación llamada a gobernar libre de odios, de revanchas, de mezquindades y con el mandato de millones de compatriotas de hacer de nuestro país una tierra grande donde los símbolos de nuestro tricolor retomen su significado". (Duque, 2018.

Resaltado, fuera del original).

Todo lo cual es corroborado por el máximo dirigente de tal facción política al afirmar -ese mismo día- que "el discurso de Ernesto [atiéndase, no el del presidente de la República], yo lo digo fríamente, sin emociones, es absolutamente necesario. Era necesario" y, en el clímax celebratorio, el cotarro se confunde en una sonora ovación al orador senatorial (Noticias Uno Colombia, 2018).

De alguna manera, esta articulación de enunciados diversos (incluso, contradictorios) viene a conferir otro sentido a un significante flotante que cuestionó con ímpetu el sector conservador del país: la combinación de todas las formas de lucha. Un eje dinamizador conecta todas las intervenciones y estaría en consonancia con el planteamiento de Lope acerca de hablarle en necio a un vulgo trifronte: copartidarios, sociedad civil y adversarios, a cada uno en sus voces y a cada quien con su velada amenaza. No hay término medio, pues hasta en sus linderos hay posibilidad de encontrar traidores, blandos y enemigos que no estén dispuestos a desacreditar al antecesor o a plantearse como adalides de la honesta cruzada contra la inmoralidad, por temor a ser alcanzados por sus propias flechas, llámeselas

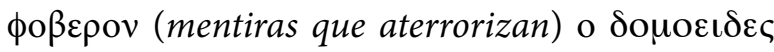
(mentiras que enardecen el ánimo).

Otro miembro del cuadro administrativo dio cuenta de la facilidad con que se puede ir de un terreno a otro, sin que se mueva un ápice la intencionalidad embaucadora y amenazante. Se trata del presidente de un gremio de comerciantes, emplazado al cargo de ministro de Defensa quien, el mismo día en que fue designado como tal por el presidente electo (17 de julio de 2018) mostró el talante alejado de las prácticas democráticas que requiere el ejercicio del cargo para el que fue nombrado, al dar a entender que cualquier situación socialmente problemática requiere del visto bueno del Estado para manifestarse: "En el ámbito social, respetamos la protesta social, pero también creemos que debe ser una protesta ordenada que verdaderamente represente los intereses de todos los colombianos y no solo de un pequeño grupo" (Botero, 2018a). Postura que "rectificó", planteando que veinte días antes "estaba hablando como dirigente gremial, yo en ese momento no había sido designado como ministro de la Defensa" (Botero, 2018b. Resaltado fuera del texto original).

Con lo expuesto, queda claramente esbozado el mecanismo de fabricación de mentiras, tan al uso por quienes usufructúan el nuevo discurso hegemónico ${ }^{26}$, mecanismo ya denunciado por Swift, ubicado en un marco argumental ${ }^{27}$ de supuesta candidez que apela a la ingenuidad, la ignorancia o el desinterés comunicativo del interlocutor, igualmente delatado por Gracián en 1647, cuando revelaba que "arguméntase la simulación al ver alcanzado su artificio y pretende engañar con la misma verdad. Muda de juego para mudar de treta, y haze artificio del no artificio, fundando su astucia en la mayor candidez" (citado por Courtine, 2011, p. 83). O, ¿ es que en verdad cualquier ciudadano medianamente reflexivo puede asumir que la designación de un

26 Recuérdense los procedimientos empleados durante la Campaña del No y lo dicho en líneas anteriores.

27 "Los marcos son las estructuras mentales gracias a las cuales entendemos el mundo e interactuamos con él" (Lakoff, 2013, p. 199). 
ministro se lleva a cabo de manera subrepticia, $a$ mansalva y sobre seguro, y que una investidura de esta importancia no es consultada con el beneficiario, máxime cuando esa designación ya había sido advertida desde el día 12 de julio por la prensa nacional (WRadio.com, 12 de julio de 2018) y fue confirmada el 17 del mismo mes por el entonces presidente electo, en el mismo acto y con el mismo auditorio -Cumbre Concordia América-, en que el neoministro lanzó su propuesta de limitar la protesta social. Adicionalmente, llaman la atención los calificativos con que el presidente perfila al señor Botero, los que reafirman el conocimiento previo de sus posturas ideológicas y políticas:

Quiero acá en este gran encuentro de Concordia, anunciarles a los colombianos que vamos a tener un nuevo ministro de Defensa con una gran experiencia gerencial, con un gran amor por Colombia. Una persona que le ha servido a muchos sectores de nuestro país, que tiene carácter, que mira a los ojos, que es transparente y que me va a acompañar por la recuperación de la seguridad, y es el doctor Guillermo Botero. (Duque, 2018b).

Se trata, como puede apreciarse, de unas líneas argumentales que van en la dirección de apuntalar la hegemonía de un segmento dirigente que, aunque pareciera tratarse de voces en contrapunto, en realidad, constituyen una composición sinfónica en la que convergen y se apoyan los diversos instrumentos, siempre con el tempo que ha definido el compositor o, en el peor de los casos, el director. De esta manera, se obtiene un ritmo particular que, en el caso que nos ocupa, bien muestra una sucesión regulada de elementos fuertes y débiles, o de condiciones opuestas y diferentes (Oxford University Press, 1971, p. 2537), acerca de las demandas sociales, pasando por el tamiz de unas élites que deciden a partir de su sistema de valores y, con base en él, formulan objetivos, instrumentos y vías para la definición de las políticas públicas (Sabatier y Jenkins-Smith, 1993, p. 17) ${ }^{28}$.

28 Con estas premisas, no resulta extraño que tras los desempeños de los actores visibles en el tinglado haya otros creadores de los diálogos y las acciones, como ocurre en cualquier pieza teatral. En este caso, un evidente dramaturgo (Álvaro Uribe Vélez) y unos ayudantes de dirección que hicieron parte de su equipo de gobierno (2002-2010) que hoy jalonan las acciones de otros actores, y no

\section{Una performance anacrónica}

Con pretensiones de transitoria conclusión, se torna indispensable volver sobre la evanescencia del Estado y sobre la complejidad de su conformación y sus realizaciones, al través de ese cuerpo especializado que, en cada administración, va adoptando el halo ideológico del patrón que sustenta el discurso del grupo hegemónico. En el caso que nos ocupa, se trata de una facción de tintes conservadores que concentra la gestión profesional del Estado en sus propias estructuras de pensamiento y acción, articulando sus pretensiones de dirección con los intereses de otras élites, con las que puede compartir significantes e imaginarios.

De esta manera, pactar con el diablo se constituye en una manera de acceder al poder sin chocar con aquél y sin tener que identificarse plenamente con el grupo hegemónico, así -en el espectáculo político- se entronicen esperpentos (esto es, imágenes deformadas por el espejo cóncavo de los intereses particulares y la ideología que los unifica) que son capaces de ofrecer líneas argumentales en supuesta discordancia, pero que endurecen la dirección política, intelectual y moral de que hablara Gramsci cuando caracterizó la hegemonía. Con estas líneas argumentales se logra hablarles en necio a las masas y convencerlas de que los intereses de la élite son sus mismos intereses y, con ello, arrancarles sangre, trabajo, impuestos y aplausos, como sentenciara Lasswell.

Y, uno de los recursos mejor empleados por esta élite, es el del devil shift que -como lo vimos antes- magnifica los errores de los adversarios y minimiza los defectos de los coaligados, todo ello alrededor de unas prácticas discursivas que engloban la totalidad de desempeños en la vida social y que ubican a cada quien en una escala jerárquica que -por una parte- posibilita el acceso a sectores académicos, técnicos y administrativos que asuman el halo ideológico del patrón, $y$-por otra- aglutina en lo más bajo a una mayoría que solo podrá salir de allí con la construcción de prácticas discursivas

exclusivamente mediante la ubicación de jalones o marcas en el desarrollo de los procesos, sino con intervenciones directas en la formulación de políticas públicas, tal como ocurre en el caso del actual Ministerio de Educación Nacional, sobre el que se cierne la presencia dominante y directriz de una antigua ministra de educación y otras integrantes de su equipo de trabajo. 
que le permitan conformar Estado, es decir, que le atribuyan la función de la hegemonía.

En una dirección complementaria, resulta pertinente precisar la significación política como resultante de la participación en escenarios y formulaciones discursivas que dan cuenta implícitamente de cualquier acción humana (individual o social), en la medida en que "todo es político, incluso la filosofía [...] y la única 'filosofía' es la historia en acto, o sea, la vida misma” (Gramsci, 2007, p. 281), con la aclaración de que el número de significantes es finito y su potencial vacuidad es sorteada al ser asumidos en el seno de un imaginario que sustenta la hegemonía que los actualiza con nuevos contenidos, acordes con sus dispositivos ideológicos.

Igualmente, aquí surge la necesidad de destacar que el actual discurso, resultado de significantes flotantes que han adquirido un sentido que quiere escuchar un sector de la población, se ha bifurcado en configuraciones discursivas que parecieran estar en contradicción pero que, como se ha visto, convergen en una misma conceptualización de país, Estado y gobernanza: lo cual puede entenderse como resultado legítimo de cualquier acción política que se ha tornado hegemónica, sin que ello implique una postura ética propia de Estados democráticos, con el agravante de que es ésta la primera vez que el aparato institucional asume el doblepensar, de manera abierta, como expresión simbólica del Estado y eso debe llamar la atención de la ciudadanía y, cómo no, de los analistas, en tanto no necesariamente va en la dirección de reforzar "los valores de la democracia, la identidad nacional y la solidaridad", de que hablara Oszlak (2005, párr. 2). Y, como faceta complementaria, vale asociar este procedimiento del aparato con la postura del partido de gobierno y entender que, mancomunados, se constituyen en estrategia mediológica encaminada a restar alcances al discurso alternativo que pueda conformar la oposición con miras a convertirse en alternativa real de poder.

Esta fusión ideológico-pragmática resulta de capital imortancia para la constitución de sentido político en las actuales condiciones de la arena colombiana y requerirá análisis de más largo aliento y mayores implicaciones teóricas y metodológicas.
Finalmente, se modela aquí el esbozo de una configuración interpretativa que aboga porque toda esta significación remozada (vinos nuevos en odres viejos) no renueve el vinagre de imaginarios sangrientos y desesperanzados, de discursos fundados en el odio que busca la eliminación física del adversario, en una sociedad cada vez más inequitativa e insolidaria. En otras palabras, que pueda alejarse el temor de que el pacto que la élite acaba de asumir nos lleve a escuchar, como en el texto de Arreola: "A estas alturas, señor mío, resulta por demás una presentación. Estoy completamente a sus órdenes". Todo lo cual abre la puerta a potenciales formas de cooptar voluntades y acciones, en aras de fortalecer la hegemonía que han venido construyendo los intereses articulados en el actual proyecto político del país.

\section{Referencias}

Arreola, J. J. (1997). Un pacto con el diablo. En Narrativa completa. (pp. 266-272). México: Alfaguara.

Botero, G. (2018a) Sobre la protesta social. Semana.com. Recuperado de https://www.semana.com/Item/Arti cleAsync/575697? nextId=575706

Botero, G. (2018b) Rectificación. RcnRadio.com. Recuperado de https://www.rcnradio.com/politica/ propuesta-de-regular-protesta-social-es-temacerrado-ministro-de-defensa

Castoriadis, C. (1997). El avance de la insignificancia, Buenos Aires: Editorial Universitaria de Buenos Aires.

Castoriadis, C. (2013). La institución imaginaria de la sociedad. Buenos Aires: Tusquets Editores.

Centro Democrático. (2018). La herencia de Santos: un país..., El Tiempo, Bogotá, martes 7 de agosto de 2018, pp. 1-7

Coronell, D. (6 de marzo de 2017). La grabación. Semana. com. Recuperado de https://www.semana.com/opinion/articulo/daniel-coronell-opinion-audio-completo-de-la-entrevista-de-juan-carlos-velez/527258

Correa M., J. I. (2019) La (de)formación política como lógica de la construcción de hegemonía. (Tesis de doctorado). Universidad Externado de Colombia. Bogotá.

Correa M., J. I. y Dimaté R., C. (2011). El análisis político del discurso: diálogo entre ciencias del lenguaje y ciencia política. Revista Folios, 33, 95-106. 
Courtine, J. J. (2011). Introducción y notas. En El arte de la mentira política (pp. 82-87). Madrid: Ediciones sequitur.

Charaudeau, P. (1983). Langage et discours. Eléments de sémiolinguistique (Théorie et pratique). París: Hachette.

Dimaté R., C. (2019) La política pública en educación: coalición y cambio (1982-2007). (Tesis de doctorado). Universidad Externado de Colombia, Bogotá.

Duque, I. (2018a) El pacto por Colombia. Discurso de posesión. ElHeraldo.co. Recuperado de https:// www.elheraldo.co/archivo/lea-aqui-el-discurso-deposesion-de-ivan-duque-528175

Duque, I. (2018b) Guillermo Botero será el ministro de Defensa de Duque. ElColombiano.com. Recuperado de http://www.elcolombiano.com/colombia/politica/ivan-duque-designo-a-guillermo-botero-comosu-ministro-de-defensa-CD9014501.

Dye, T. R. (1987). Understanding public policy. 6th. ed. Englewoods Cliffs: Prentice-Hall.

Eco, U. (2013). Construir al enemigo. Bogotá: Ramdom House Mondadori.

Edelman, M. (2002). La construcción del espectáculo político. Buenos Aires: Ediciones Manantial.

Foucault, M. (1985). Las palabras y las cosas. Barcelona: Editorial Planeta-De Agostini.

Foucault, M. (2013). La arqueología del saber. México: Siglo XXI Editores.

González E., M. F. (2018). Claves del discurso de Iván Duque. ElTiempo.com. Recuperado de https:// www.eltiempo.com/politica/gobierno/claves-deldiscurso-de-ivan-duque-desde-que-asumio-la-presidencia- 262860

Gramsci, A. (2007). Antología. México: Siglo xxi Editores.

Habermas, J. (1999). La inclusión del otro. Estudios de teoría política. Madrid: Paidos Ibérica.

Howarth, D. (1997). La teoría del discurso. En D. Marsh y G. Stoker (eds.), Teoría y métodos de la ciencia política (pp. 125-142). Madrid: Alianza Editorial.

Laclau, E. y Mouffe, Ch. (2006). Hegemonía y estrategia socialista. Hacia una radicalización de la democracia. Buenos Aires: Fondo de Cultura Económica.

Laclau, E. (1981). Teorías marxistas del estado: debates y perspectivas, en N. Lechner, Estado y política en América Latina. México: Siglo xxi Editores.

Lakoff, G. (2013). Puntos de reflexión. Manual del progresista. Barcelona: Ediciones Península.
Lakoff, G. y Johnson, M. (2015). Metáforas de la vida cotidiana. Madrid: Ediciones Cátedra.

Lechner, N. (ed.) (2000). Estado y política en América Latina. México: Siglo xxi Editores.

Lope Blanch, J. M. (1987). La estructura de la cláusula en un discurso político. En Análisis gramatical del discurso. México: unAM.

Majone, G. (2005). Evidencia, argumentación y persuasión en la formulación de políticas. México: Colegio Nacional de Ciencias Políticas y Administración Pública y Fondo de Cultura Económica.

Marx, C. y Engels, F. (1973). La ideología alemana. En Obras escogidas. Moscú: Editorial Progreso.

Mouffe, Ch. (2007). En torno a lo político. Buenos Aires: Fondo de Cultura Económica.

Mouffe, Ch. (2014). Agonística. Pensar el mundo políticamente. Buenos Aires: Fondo de Cultura Económica.

Noticias Uno Colombia (7 de agosto de 2018). Exclusivo: cómo habla el uribismo en privado [Archivo de video]. Recuperado de https://www.youtube.com/ watch?v=jEDXwS2nyz0

O’Donell, G., Iazzetta O. y Vargas; J. (Comps.) (2003) Democracia, desarrollo humano y ciudadanía. Reflexiones sobre la calidad de la democracia en América Latina. Rosario: PNUd y Homo Sapiens Ediciones.

Orwell, G. (1946) Politics and the English Language. Recuperado de http://www.orwell.ru/library/essays/ politics/english/e_polit

Orwell, G. (2016). 1984. Bogotá: Penguin Random House.

Orwell, G. (2010). La libertad de prensa. En Rebelión en la granja. (pp. 25-43). Bogotá: Editorial Planeta Colombiana.

Oszlak, O. (2005), La reconstrucción del estado. Recuperado de www.claudiabernazza.com.ar/htm/ biblioteca/oszlak1.doc

Oszlak, O. (2007). Formación histórica del Estado en América Latina: elementos teórico-metodológicos para su estudio. Buenos Aires: Proyecto de Modernización del Estado, Jefatura de Gabinete de Ministros de la Nación.

Oxford University Press (1971). The Compact Edition of the Oxford English Dictionary. Oxford.

Parsons, W. (2007). Políticas públicas. Una introducción a la teoría y la práctica del análisis de políticas públicas, Buenos Aires: Flacso-México. 
Peirce, Ch. S. (1978). La ciencia de la semiótica. Buenos Aires: Nueva Visión.

Pessoa, F. (1989). Fausto o El horror de conocer. Madrid: Editorial Tecnos.

RCNRadio.com (8 de agosto de 2018). Tema de regular protesta social es un "capítulo cerrado": ministro de Defensa. Recuperado de https://www.rcnradio.com/ politica/propuesta-de-regular-protesta-social-estema-cerrado-ministro-de-defensa

Ritzer, G. (1996). Teoría sociológica clásica. México: McGraw-Hill.

Roth, A. (2006). Políticas públicas: formulación, implementación y evaluación. Bogotá: Ediciones Aurora.

Sabatier, P. A. (Ed.) (2007). Theories of the Policy Process. Boulder: Westview Press.

Sabatier, P. A. y Jenkins-Smith, H.C. (eds.) (1993). Policy Change and Learning. An Advocacy Coalition Approach. Boulder: Westview Press.

Schmitt, C. (2004). Carl Schmitt, teólogo de la política. México: Fondo de Cultura Económica. Prólogo y selección de textos: Héctor Orestes Aguilar.

Semana.com (18 de julio de 2018). Nuevo ministro de Defensa propone regular la protesta. Recuperado de https://www.semana.com/Item/ArticleAsync/5756 97 ?nextId=575706

Semana.com (19 de diciembre de 2016) "Las mentiras" de las campañas del No, según el Consejo de Estado. Semana.com. Recuperado de https://www.semana. com/nacion/articulo/el-consejo-de-estado-diceque-se-le-mintio-al-electorado-en-campanasdel-no/510040

Swift, J. (2000). Ideas para sobrevivir a la conjura de los necios. Barcelona: Ediciones Península.

Swift, J. (2011). El arte de la mentira política. Madrid: Ediciones sequitur.

Valle Inclán (s.f.). Luces de bohemia. Recuperado de http://www.cervantesvirtual.com/obra-visor/lucesde-bohemia-esperpento-875782/html/f061ab8096cc-4bec-9e5d-fcb779e7bed5_3.html

Van Dijk, T. (1996). Ideología y análisis del discurso ideológico. Recuperado de http://www.discursos.org/ oldarticles/Ideolog\%EDa\%20y\%20an\%E1lisis\%20 del\%20discurso.pdf
Vega, Lope de (1609). Arte nuevo de hacer comedias en este tiempo. Recuperado de http://www.cervantesvirtual. com/obra-visor/arte-nuevo-de-hacer-comediasen-este-tiempo--0/html/ffble6c0-82b1-11df-acc7002185ce6064_4.html

Vélez, J. C. (2016a). Audio entrevista Juan Carlos Vélez Uribe [Archivo de video]. Recuperado de https:// www.youtube.com/watch?v=9Jwuk-fGbrs

Vélez, J. C. (2016b). “El 'No' ha sido la campaña más barata y más efectiva de la historia”. ElUniversal.com. co. Recuperado de https://www.eluniversal.com.co/ colombia/el-no-ha-sido-la-campana-mas-barata-ymas-efectiva-de-la-historia-237149-EXEU344909

Vélez, J. C. (2016c). "Estábamos buscando que la gente saliera a votar verraca”. ElColombiano.com. Recuperado de: http://www.elcolombiano.com/ colombia/acuerdos-de-gobierno-y-farc/entrevistaa-juan-carlos-velez-sobre-la-estrategia-de-lacampana-del-no-en-el-plebiscito-CE5116400

Verón, E. (2004). La semiosis social. Buenos Aires: Editorial Gedisa.

Weber, M. (2000). ¿Qué es la burocracia? Recuperado de https://ucema.edu.ar/u/ame/Weber_burocracia.pdf

Weber, M. (2012). La política como vocación. Recuperado de http://www.academia.edu/20847549/ La-poltica-como-vocacion-M.-Weber

WRadio.com (12 de julio de 2018). Guillermo Botero sería ministro de Defensa del gobierno de Iván Duque. WRadio.com.co. Recuperado de http:// www.wradio.com.co/noticias/actualidad/guillermobotero-seria-ministro-de-defensa-del-gobierno-deivan-duque/20180712/nota/3773180.aspx 